\title{
Health Literacy of Diabetic Patients and its Impact on Disease Outcome
}

\author{
Ahmed A. Abdul-Hasan* \\ Batool A. Gh. Yassin*
}

\author{
MBChB, MSc \\ FICM-CM
}

\begin{abstract}
:
Background: Diabetes is one of commonly and costly chronic health issues and a major cause of morbidity and mortality among other non-communicable diseases. Diabetes patients' literacy about their diseases is to be addressed as a active factor of the disease outcome.

Fac Med Baghdad 2018; Vol.60, No.1 Received: Dec., 2017 Accepted: Mar., 2018

Objectives: The objectives of the current study were to determine the overall health literacy level among diabetic patients attending the PHC centers and to test the association between the measured health literacy and their glycemic control.

Methods: A cross section study was conducted on a sample of randomly selected diabetic patients attending primary health care centers in Baghdad during the period from $15^{\text {th }}$ July 2016 to $15^{\text {th }}$ April 2017. Relevant demographic data were recorded and a specially designed tool was used to measure health literacy among diabetic patients, it consist of 15 question covering all aspects of health literacy (Scores 1 to 5 each question). The presenceof diabeticcomplications were recorded and glycemic control of patients was documented by $\mathrm{Hb}_{\mathrm{Alc}}$.

Results: With a total literacy score ranging from 15-75, the mean score of the patients in the current study was (mean $=43.34 \pm 11.1 \mathrm{SD}$ ), and their recent $\mathrm{HB}_{\mathrm{Alc}}$ found to be ranging from 6.4 to 13.4 $($ mean $=10.25 \pm 1 \mathrm{SD})$. A statistically significant association was found between patient literacy score and glycemic control $(\mathrm{P}<0.001)$, and the presence of complications $(\mathrm{P}=0.026)$.

Conclusion: The glycemic control of diabetic patients (measured by HBA1c) and the presence of the diabetic complication might be affected by the patient literacy about his disease.

Keywords: HBA1c, Health literacy Score, Diabetes Mellitus, Iraq.
\end{abstract}

\section{Introduction:}

Non-communicable diseases (NCDs), (Heart disease, cerebral accidents and cancers and diabetes and its complications) are common causes of mortality and morbidity worldwide. The number of diabetics has risen from 108 million in 1980 to 422 million in 2014. with global prevalence among adults (>18 years) risen from $4.7 \%$ in 1980 to $8.5 \%$ in $2014^{(1)}$. Diabetes prevalence has been rising more rapidly in middle- and low-income countries (1). Diabetes Mellitus was listed the fifteenth as a global cause of death in 1990, then became the $9^{\text {th }}$ in 2010 $\left(12^{\text {th }} \text { in men. } 6^{\text {th }} \text { in women }\right)^{(2)}$. Health Literacy has been defined (WHO) as:- the cognitive and social skills which determine the motivation and ability of individuals to gain access to understand and use information in ways which promote and maintain good health. Health Literacy means more than being able to read pamphlets and successfully make appointments. By improving people's access to health information and their capacity to use it effectively, health literacy is critical to empowerment ${ }^{(2)}$. Generally, health literacy composed of mainly 15 components that include; Literacy, Interaction, Comprehension, Numeracy, Information seeking, Application/function, Decision making /critical thinking, Evaluation, Responsibility, Confidence, Navigation, Social support for health

* Dept. of Family and Community Medicine, College of Medicine, University of Baghdad. dr.ahmed8427@gmail.com
Rights and access to health information and services, Trust and Motivation ${ }^{(3)}$ Health literacy should be promoted because almost always a complex therapeutic regimen is needed to manage or control diabetes, but patients with diabetes experience an overwhelming responsibility of navigating healthcare systems and making appropriate health choices $^{(4)}$. The health literacy level of patients also serves as a guide for healthcare providers on how to communicate with patients effectively ${ }^{(2)}$. However, health literacy and its relation to diabetes and outcomes for diabetic patients is yet to be investigated in Iraq. This study aimed to determine the association between health literacy levels and health outcomes for patients with diabetes Type II in primary health care centers in Baghdad.

\section{Patients and Methods:}

A cross sectional study was carried out from $15^{\text {th }}$ July 2016 to $15^{\text {th }}$ April 2017 on diabetic patient attending primary health care centers (PHCc) in Baghdad. A total of 26 PHCC was included, two PHCc were selected randomly from each Health District in Baghdad. All diabetic patients attending the selected PHCc at the study visit were included in the study. The PHCc were visited four days per week, four hours a day. A specially designed questionnaire form was prepared and evaluated by experts in the field to cover all 15 components of health literacy and be feasible in our community for assessing health literacy among diabetic patients. 
The scoring of health literacy done by asking all patients 15 questions that cover all components of health literacy, each question score 1 to 5 points with total score of 15 to 75 points. Total score is calculated for each patient. Demographic data (ID, gender, age, address, marital state, education level, occupation, family size, income) and disease related data (duration of diabetes, treatment type and duration, presence of other chronic disease, number of hospital admissions due to diabetes, number of doctor visits and its causes) were also recorded in the questionnaire form in addition to the most recent $\mathrm{Hb}_{\mathrm{Alc}}$ if available; otherwise blood sample was taken (after taking patient's verbal consent) by the researcher under aseptic technique and conditions, and send to a private laboratory and the glycosylated hemoglobin level was measured and documented with help of a professional lab personnel. The presence of diabetes complication which reported by the patient or documented by their doctors, were also recorded in the data collection form. Pilot study was done on five patients, and the data was recorded then, two weeks later the same patients were subjected to the study again and similar data obtained from each patient.

\section{Statistical Analysis:}

Data was entered to computer using Statistical Package for Social Sciences (SPSS) version 24. Continuous variables were presented as mean \pm standard deviation (SD) and categorical variables were presented as frequencies and percentages. Chisquare test was used for testing the association between categorical variables, independent student's T-test was used for testing the differences between two means of continuous variables. Pearson correlation were used to test the correlation between variables, ANOVA was used to test the differences between more than two means. $\mathrm{P}$ value of $<0.05$ was considered to be statistically significant.

\section{Results:}

A total of 447 patients were included in the study; 267 males $(59.7 \%)$ and 180 females $(40.3 \%)$ with a male to female ratio about $3: 2$ (table 1). Their literacy score ranged from 18-67 with a mean of $43.34 \pm 11.1$. The mean literacy score of males was $43.3 \pm 11.01$ and that of females was $43.4 \pm 11.2$. The differences between the mean literacy scores of males and females was statistically not significant (Table 2). Regarding age; although the health literacy score was higher among older age group, yet the differences in scores among different age groups were statistically not significant (table 2), whereas health literacy score increased with increased level of education differences between the mean literacy scores among different educational levels were statistically significant $(\mathrm{P}<0.001)$ (Table 2). The level of $\mathrm{HbA} 1 \mathrm{c}$ of the studied patients ranged from $6.4-13.4 \mathrm{mmol} / \mathrm{mol}(10.25 \pm 1.01)$ the correlation between literacy score and glycemic control showed a negative moderate significant correlation $(\mathrm{r}=$ $0.784, \mathrm{P}<0.001$ ) (Figure 1). almost all of the patients in the current study were with poor glycemic control (>7). Average HbA1c is 10.25 correspond to average RBS of about $247 \mathrm{mg} / \mathrm{dl}$. Searching for complications of diabetes mellitus (Table 3) showed that $85.5 \%$ of the diabetic patients reports no complications and their mean total health literacy score was higher $(43.82 \pm 11.1)$ than that of those with documented complications due to diabetes mellitus $(40.51 \pm 10.4)$ and the difference in mean scores was statistically significant $(\mathrm{P}=0.026)$.

Table 1: Distribution of diabetic patients by gender

\begin{tabular}{lll}
\hline Gender & No. & $\%$ \\
\hline Males & 267 & 59.7 \\
\hline Females & 180 & 40.3 \\
\hline Total & 447 & 100.0 \\
\hline
\end{tabular}

Table 2; Distribution of diabetic patients by their literacy score and gender

\begin{tabular}{|c|c|c|c|}
\hline \multicolumn{2}{|l|}{ Variables } & $\begin{array}{l}\text { Literacy score (Mean } \\
\text { SD) }\end{array}$ & ${ }^{ \pm} \mathrm{P}$ value \\
\hline \multicolumn{4}{|l|}{ Gender } \\
\hline \multicolumn{2}{|l|}{ Male (267) } & $43.31 \pm 11.01$ & 0.95 \\
\hline \multicolumn{2}{|l|}{ Females (180) } & $43.37 \pm 11.2$ & \\
\hline \multirow{3}{*}{ Age (in years) } & $<40$ & $43.10 \pm 11.465$ & \multirow{3}{*}{0.4} \\
\hline & $41-60$ & $42.63 \pm 10.646$ & \\
\hline & $>60$ & $44.36 \pm 11.047$ & \\
\hline \multicolumn{4}{|l|}{ Education } \\
\hline Illiterate/Can't & & $21.57 \pm 2.643$ & \multirow{5}{*}{$<0.001$} \\
\hline \multicolumn{2}{|l|}{ Read \& Write } & $30.96 \pm 5.521$ & \\
\hline \multicolumn{2}{|l|}{ Primary Edu. } & $44.17 \pm 5.074$ & \\
\hline \multicolumn{2}{|c|}{ Secondary/Intermediate } & $58.31 \pm 4.986$ & \\
\hline \multicolumn{2}{|l|}{ College } & $63.75 \pm 1.909$ & \\
\hline
\end{tabular}




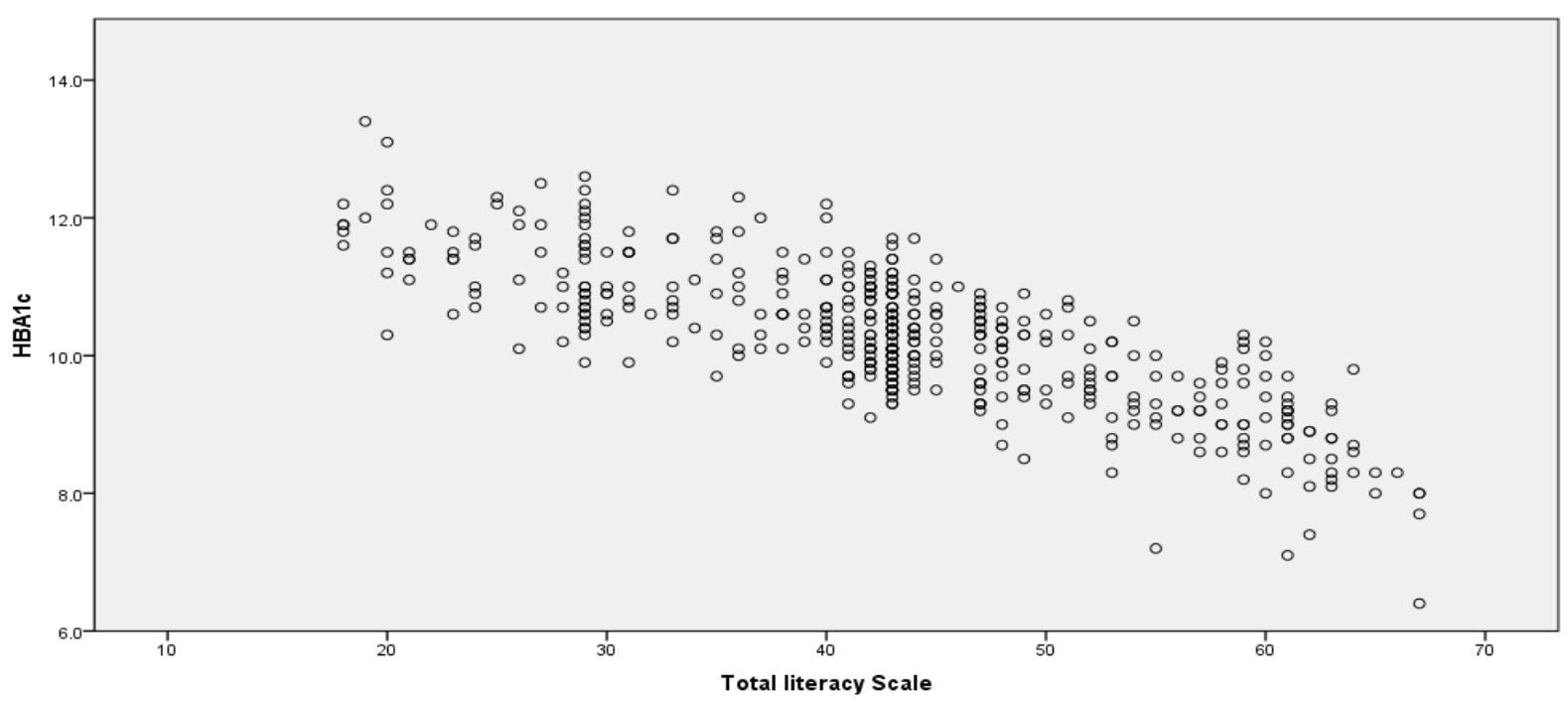

Figure 1; Correlation between $\mathrm{Hb}_{\mathrm{Alc}}$ \& literacy score

Table 3; Distribution of diabetic patients by the presence of complication and literacy score Mean of total

ComplicationsNo. of patients (\%) literacy score $\pm \mathrm{P}$ value SD

\begin{tabular}{llll} 
& \multicolumn{3}{c}{ SD } \\
\hline No & $382(85.5)$ & $43.82 \pm 11.1$ & \multirow{2}{*}{0.026} \\
\hline Yes & $65(14.5)$ & $40.51 \pm 10.4$ & \\
\hline
\end{tabular}

\section{Discussion:}

Participation of diabetic patients in the health care process has been known as an important factor of good disease management as the disease usually necessitate extensive, continuous patient self-care ${ }^{(5)}$. The current study revealed that mean health literacy scores were nearly the same among both males and females. Salimi et al ${ }^{(6)}$, on studying diabetic patients in Shahroud city of Iran in 2016 found that diabetic literacy score was higher among men than women, higher in more educated patients, gender difference in Salimi study could be due social and cultural differences and/or different access to educations or health promoting. In the current study glycemic control was significantly associated with health score (negative relation between $\mathrm{HB}_{\mathrm{Alc}}$ and score of health literacy). This finding is similar to that reported in western Jamaica ${ }^{(7)}$. on studying the impact of patients' health literacy on health outcomes in diabetic patients at health centers. The current study revealed that higher health literacy scores were associated with less complication. This finding is corresponding with that of Schillinger et al., $2002^{(8)}$ in their study which stated that patients with insufficient health literacy got unsatisfactory clinical outcomes. Other studies ${ }^{(8,10)}$ also noticed more diabetes complications in patients with lower health literacy, while another study ${ }^{(6)}$ it was found that the significant differences vanished after adjustment for confounders these differences need to be furtherly investigated. Williams et al., $1998^{(9)}$, Kim et al, 2004 ${ }^{(10)}$, Rothman et al., 2004 $4^{(11)}$ and Morris et al., $2006^{(12)}$ did not completely agree with our results, this difference could be explained by insufficient data, low power of study, different sensitivity of the assessment tools, methods and measurement of glycemic control.

\section{Conclusions:}

Gender and age did not affect the literacy score of diabetic patients. The mean total health literacy score increased significantly with higher educational level. Most of the patients in the current study were with poor glycemic control (above $7 \mathrm{mmol} / \mathrm{mol}$ ), the correlation between literacy score and glycemic control showed a negative moderate significant correlation. The presence of diabetic complications was significantly higher in those who score less in health literacy assessment than those who scores higher.

\section{Recommendations:}

Having higher level of literacy and knowledge about the disease and its related issues tend to improve the level of glycemic control in diabetics, and make them significantly less likely to develop diabetic complications.

Enhancing patient education and knowledge may give better public health outcome regarding this chronic disease and ameliorate its burden on the patient and community More attention and resources dedicated to educational programs to enhance health literacy may be beneficial and more cost effective than spending heavy resources on dealing with late diabetic complications in late stages.

\section{Authors contributions:}

Dr. Ahmed Ali Abdul-Hasan, Researcher.

Ass. Prof. Batool A. Gh. Yassin, Supervisor.

\section{References:}

1. Centers for Disease Control and Prevention. National Diabetes Statistics Report: Estimates of Diabetes and Its Burden in the United States, 2014. Atlanta, GA: U.S. Department of Health and Human Services: 2014. 
http://www.cdc.gov/diabetes/pubs/statsreport14/nati onal-diabetes-report-web.pdf

2. World Health Organization, 2014. Track 2: Health literacy and health behaviour. In 7th Global Conference on Health Promotion: track themes. Available at: http://www. who. int/healthpromotion/conferences/7gchp/track2/en/. Accessed 2017 Oct (Vol. 7).

3. Sørensen K, Van den Broucke S, Fullam J, Doyle $G$, Pelikan J, Slonska Z, Brand H. Health literacy and public health: a systematic review and integration of definitions and models. BMC public health. 2012 Dec;12(1):80.

4. Bhutani J, Bhutani S. Worldwide burden of diabetes. Indian journal of endocrinology and metabolism. 2014 Nov;18(6):868. [Last accessed on 2013 Dec 16].

5. Ishikawa H., Takeuchi T. and Yano E.; Measuring Functional, Communicative, and Critical Health Literacy among Diabetic Patients. Diabetes Care, May 2008.

6. Salimi M, Sarchahi S, Zolfaghari P, Daghyanous B, Mozaffari H, Montazeri M, Sohrabi MB. Health Literacy among Patients with Diabetes Mellitus Type 2 in Northeast Area of Iran. International Journal of Health Studies. 2017 Jan 1;3(1).

7. Singh SG, Aiken J. The effect of health literacy level on health outcomes in patients with diabetes at a type $v$ health centre in Western Jamaica. International Journal of Nursing Sciences. 2017 Jul 10;4(3):266-70.

8. Schillinger D, Grumbach K, Piette J, Wang F, Osmond D, Daher C, Palacios J, Sullivan GD, Bindman AB: Association of health literacy with diabetes outcomes. JAMA 288:475-482, 2002

9. Williams MV, Baker DW, Parker RM, Nurss JR. Relationship of functional health literacy to patients' knowledge of their chronic disease: a study of patients with hypertension and diabetes. Archives of internal medicine. 1998 Jan 26;158(2): 166-72.

10. Kim S, Love F, Quistberg DA, Shea JA. Association of health literacy with self-management behavior in patients with diabetes. Diabetes care. 2004 Dec 1;27(12):2980-2.

11. Rothman RL, DeWalt DA, Malone R, Bryant B, Shintani A, Crigler B, Weinberger M, Pignone $M$. Influence of patient literacy on the effectiveness of a primary care-based diabetes disease management program. Jama. 2004 Oct 13;292(14):1711-6.

12. Morris NS, MacLean CD, Littenberg B. Literacy and health outcomes: a cross-sectional study in 1002 adults with diabetes. BMC family practice. 2006 Dec;7(1):49. 